Wales population has shown that in the community as a whole iron deficiency is no more common in those with dysphagia or webs than in those without (Elwood, Jacobs, Pitman, and Entwistle, 1964). Patients sent to hospital, as the present cases were, tend to be selected from the general population by reason of their anaemia, while those with webs who are not anaemic might tend not to be seen. The criteria for the radiological diagnosis of post-cricoid webs have been clarified by Pitman and Fraser (1965). They have shown that this lesion must be distinguished from the appearance due to varicosity of the post-cricoid venous plexus. The $x$-ray pictures in the present cases were reviewed by Dr. Pitman, and the diagnosis of post-cricoid web was confirmed in all but Case 1, where the appearance was felt to be equivocal. It is of interest that the web in Case 1 could not be seen radiologically after full treatment with iron. In Case 5, however, the web was discovered only after the iron-deficiency anaemia had been cured.

Previous reports have emphasized that achlorhydria is common in patients with the Paterson-Kelly syndrome (Moersch and Conner, 1926 ; Jacobs and Kilpatrick, 1964). Badenoch, Evans, and Richards (1957) found dysphagia only in those patients who had both iron deficiency and gastric atrophy. Gastric-function tests in the present cases were carried out by different techniques, so that no quantitative comparison can be made. Cases 2-4 undoubtedly had acid secretion within the normal range. Cases 1 and 2 were subjected to a continuous histamine infusion by the technique of Lawrie et al. (1964), and the maximum secretory rate of $4 \mathrm{mEq} /$ hour in Case 1 is unequivocally subnormal. The Schilling test in Cases 1 and 2 was within normal limits. Gastric biopsy was not performed in any of the cases. Gastric atrophy is rare in adolescence and becomes more common with increasing age. The significance of its presence in one of the five cases is difficult to assess.

There was no evidence of steatorrhoea in any of the patients. Iron absorption from a test meal was measured in three patients before the anaemia was treated. In two, with normal gastric secretion of acid, increased absorption of iron was found, as would be expected with a severe iron-deficiency anaemia. In the third patient, a boy aged 14 (Case 1 ), only $4 \%$ of the oral dose of iron was absorbed despite his severe anaemia. This patient had a low acid output in response to histamine, and the failure to increase his iron absorption is in keeping with the findings in other such patients with hypochlorhydria or achlorhydria (Goldberg, Lochhead, and Dagg, 1963 ; Peters, Lawrie, and Jacobs, unpublished).

Severe atrophic changes in the tongue were not seen in any of the present cases ; nor was koilonychia present. The clinical picture was otherwise similar to that seen in older hospital patients in that iron deficiency was present in all cases and there was marked angular stomatitis in three of them. The accidental discovery of five patients below the age of 20 with post-cricoid webs indicates that this condition may occur at an earlier age than has been previously recognized.

\section{Summary}

The cases of five patients in whom post-cricoid webs were discovered during adolescence are described. All had irondeficiency anaemia when first seen, and in one case there was evidence of gastric atrophy and impaired iron absorption.

We should like to thank Professor H. Scarborough for his helpful criticism and the physicians under whose care the patients were admitted to hospital for permission to publish the case histories.

\section{REFERENCES}

Badenoch, J., Evans, J. R., and Richards, W. C. D. (1957). Brit. Y. Haemat., 3, 175,

Brumfitt, W. (1960). Quart. F. Med., 29, 1.

Elwood, P. C., Jacobs, A., Pitman, R. G., and Entwistle, C. C. (1964). Lancet, 2, 716 .

Goldberg, A., Lochhead, A. C., and Dagg, J. H. (1963). Ibid., 1, 848.

Jacobs, A., and Kilpatrick, G.'S. (1964). Brit. med. Ұ., 2, 79.

Jones, R. F. McN. (1961). 7. Laryng., 75, 529.

Kelly, A. B. (1919). Ibid., 34, 285.

Kilpatrick, G. S. (1961). Brit. med. 7., 2, 1736.

Lawrie, J. H., Smith, G. M. R., and Forrest, A. P. M. (1964). Lancet, $2,270$.

Leonard, B. J. (1954). Ibid., 1, 899.

Leonard, B. J. (1954). Ibid., 1, 899. (1926). Arch. Otolaryng., 4, 112.

Molan, W. (1925). Geneesk. Bl., 24, 325.

Paterson, D. R. (1919). F. Laryng., 34, 289.

Pitman, R. G., and Fraser, G. M. (1965). Clin. Radiol., 16, 34.

Shorthouse, P. H., and King, R. C. (1951). Brit. med. F., 2, 256.

Smiley, T. B., McDowell, R. F. C., and Costello, W. T. (1963). Lancet, 2, 7 .

Thomson, M. L. (1943). Brit. med. 7., 2, 454.

Witts, L. J. (1930). Guy's Hosp. Rep., 80, 417.

Witts, (1931). Ibid., 81, 193

Wynder, E. L., and Fryer, J. H. (1958). Ann. intern. Med., 49, 1106.

\title{
Jaundice During Treatment with an Oral Contraceptive, Lyndiol
}

\author{
GÖRAN CULLBERG,* M.B.; ROLF LUNDSTRÖM,† M.D. ; UNNE STENRAM,‡ M.D.
}

Brit. med. F., 1965, 1, 695-697

The possibility of liver damage during treatment with oral contraceptives has recently been considered in the British Medical fournal. As only a few cases of jaundice have been reported (see Table), and as attention should be paid to all possible adverse effects of drugs, we present the following case of icterus which we suspect of being caused by Lyndiol.

\section{Case Report}

The patient, a 2-para born in 1925, had been treated for pulmonary tuberculosis from 1945 to 1948. During her last pregnancy, in 1958, she developed pyelitis. She has also had cystitis several times, the last occasion being in May 1964, when sulphonamides were given and blood samples were taken. She had occasionally taken Medapan sleeping-tablets, containing heptabarbitone. She has not received any injections during the last year, and has had no contacts with other cases of jaundice.
From the beginning of July 1964 she took one tablet of Lyndiol a day. After three to four days she experienced nausea and vomited a few times, but continued to take the tablets for 10 more days. She gradually lost her appetite, got tired, and developed pruritus. At the end of July the urine became dark, and she was slightly jaundiced. She was admitted to hospital on 31 July. Her jaundice reached its maximum in the middle and end of August, then gradually subsided. She left hospital on 18 September. When seen on 7 October she felt quite well and was in full working capacity.

Investigations.-Among the laboratory data the following may be mentioned. As a rule tests were repeated, but only the most important pathological findings are given:

Serum bilirubin (25 August, $8.42 \mathrm{mg} . / 100 \mathrm{ml}$., $7.52 \mathrm{mg}$. direct-acting; serum alkaline phosphatase (8 September), 75.8

* Research Assistant of Pathology, University of Uppsala, Sweden. † Assistant Professor, Department of Epidemiology, Centrallasarettet, Eskilstuna, Sweden.

‡ Associate Professor of Pathology, University of Uppsala, Sweden. 
units, Buch and Buch (normal 2-8); thymol turbidity test (11 August), 8.5 Maclagan units (normal $<4$ ) (11 other tests on thymol turbidity and flocculation from 3 August to 7 October were all within normal limits); S.P.G.T. (3 August), 230 units (normal<30); S.G.O.T. (25 August), 52 units (normal<30); haptoglobin (28 August), $50 \mathrm{mg} . / 100 \mathrm{ml}$; prothrombin index (4. September) (Quick), 77\%; bile in urine (3 September), Schlesinger $t(+)$; bile in faeces (3 September), Schlesinger ++++ . Electrophoresis of serum proteins (7 August), total 7.5 g./100 ml. (albumin 3.97 ; globulins $\alpha_{1} 0.41, \alpha_{2} 0.47, \beta 1.25$, $\gamma$ 1.40). Haemoglobin, $9.33 \mathrm{~g} . / 100 \mathrm{ml}$. ; total blood leucocytes (25 August), 8,100/c.mm. (6\% eosinophils); sedimentation rate (25 August), $60 \mathrm{~mm} . / 1$ hour ; osmotic fragility of erythrocytes (3 September), normal ; Coombs test (3 September), direct and indirect, normal. $X$-ray examination (27 August) showed liver size normal, corresponding to $780 \mathrm{ml} . / \mathrm{sq}$. m. bơdy surface. Temperature not above $37.6^{\circ} \mathrm{C}$.

Biopsy.-Percutaneous needle biopsy of the liver was performed on 8 September, when the jaundice was regressing. Histological examination (Figs. 1 and 2): The lobular structure was preserved, with no signs of cirrhosis. The plates of liver cells were slightly distorted. The parenchymal cells varied in size, and several of them were ballooned. There was a slight variation in size and stainability of the nuclei. A few were hyperchromatic, and some chromatolytic. Some were vacuolated. There were several multinucleated cells. One cell seemed to contain 10 nuclei, and there were several cells with five to seven nuclei. There were only a few inflammatory cells in the portal tracts, and not more than might occur in "normal" livers. Occasional lymphocytes and polymorphonuclear leucocytes were seen in the lobules. Some of the Kupffer cells were prominent. There were many bile thrombi in the biliary canaliculi, and there was also bile pigment in some parenchymal and Kupffer cells. There were no bile' lakes, and bile was not encountered in the bile-ducts in the portal tracts. There was no fatty change.

Epicrisis.-The normal osmotic fragility of erythrocytes, normal Coombs test, and very low indirect-acting bilirubin in serum precluded haemolytic jaundice. The high level of alkaline phosphatases in serum and the normal thymol test 11 times out of 12 indicated obstructive jaundice. Liver biopsy showed no signs of extrahepatic obstructive jaundice, such as polymorphonuclears in the portal tracts, bile-ductule proliferation, fibroblast proliferation, bile lakes, or bile in the bile-ductules. The biopsy showed, however, numerous bile thrombi in the biliary canaliculi. There were also histological signs of hepatocellular damage. Minimal infiltrates of inflammatory cells were seen in the biopsy. This argued against viral hepatitis, as did the low fever and the fact that the thymol test was normal 11 times out of 12 .

From the above observations it seemed possible to exclude haemolytic jaundice and extrahepatic obstructive jaundice. Viral hepatitis did not seem very likely. As it is well known that Lyndiol can cause liver damage (see Table), it seemed very probable that the patient's disease was caused by the Lyndiol treatment.

\section{General Discussion}

As stated above, it is very probable that the present case of jaundice was due to treatment with Lyndiol. The following data seem characteristic of the case. Laboratory tests suggested obstructive jaundice with signs of hepatocellular damage. Liver biopsy confirmed these changes, and argued strongly against extrahepatic obstruction. A noticeable observation in the biopsy was the presence of many multinucleated cells. Their presence was certainly due to the biopsy being taken when the liver was in a phase of regeneration.

The hepatotoxicity of Lyndiol and some allied compounds is summarized in the Table, which comprises both general clinical trials of liver function and single reports of cases of jaundice. The hepatocellular damage in the present case and in those cases in the literature (see Table) is more pronounced than in pure intrahepatic obstructive jaundice as classically described in chlorpromazine jaundice, and also in methyltestosterone jaundice (Zimmerman, 1963). But all steroids do not cause exactly the same type of liver damage (Drill, 1963), and there may be some degree of cytotoxic effect (Lancet, 1962 ; Smetana, 1963). This was also found in the present case. The livercell damage accords well with the repeated observation of elevated transaminases during treatment with Lyndiol (see Table). The alkaline phosphatase level was, however, reported to be normal in several of these cases, suggesting that the cytotoxic effect may be more pronounced than the cholestatic effect

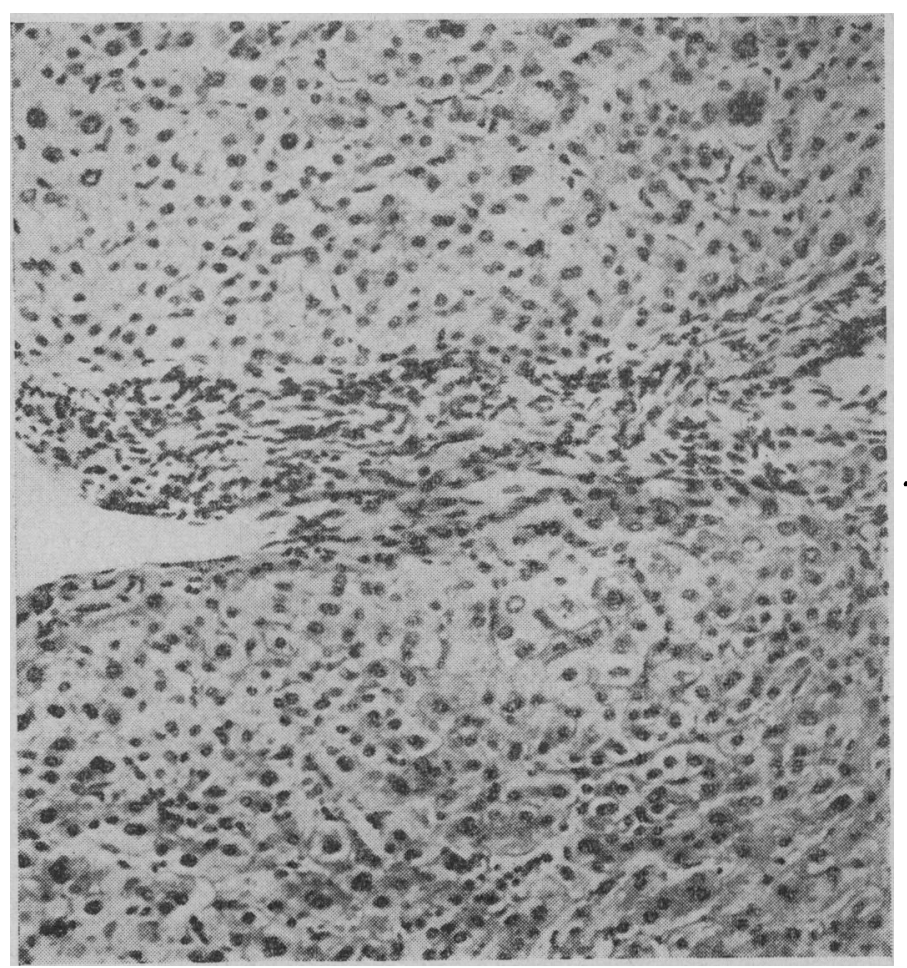

FIG. 1.-Section of liver biopsy. A portal tract is seen in the centre of the figure with about "normal" amount of inflammatory cells. The parenchymal cells and their nuclei vary in size and stainability. Many parenchymal cells are seen. Some nuclei are vacuolated. Several multinucleated cells are encountered. The one in the upper right-hand nucleated cells are encountered. The one in the upper right-hand guished in this staining. ( $\times 160$. Haematoxylin and eosin.)

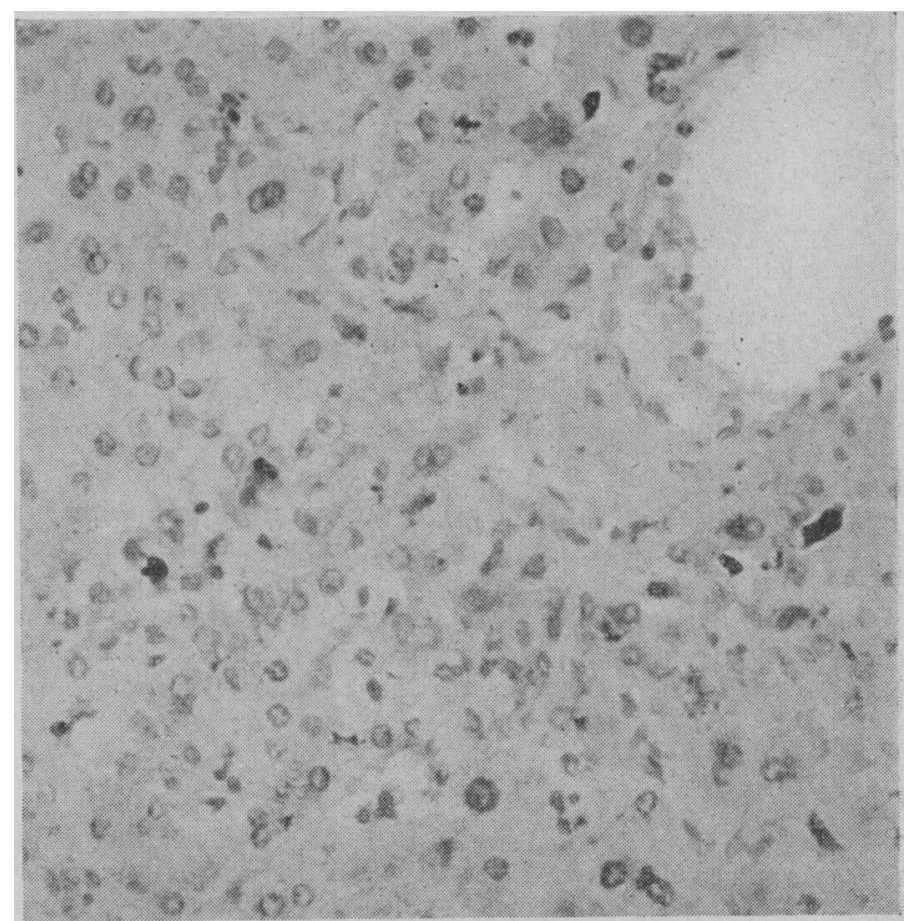

Fig. 2.-An adjacent section. Bile thrombi are seen as dark spots in the biliary canaliculi. Bile is also found in some parenchymal cells and Kupffer cells. The vessel in the upper part of the picture is a central vein. The cell polymorphism is less pronounced than in Fig. 1. $(\times 330$. Bilirubin-staining according to Hall (1960), slight counterstaining witb haematoxylin. 
Pathological Liver-function Tests in Patients Treated with Oral Contraceptives. Survey of Literature on General Clinical Trials and Solitary Cases of Yaundice

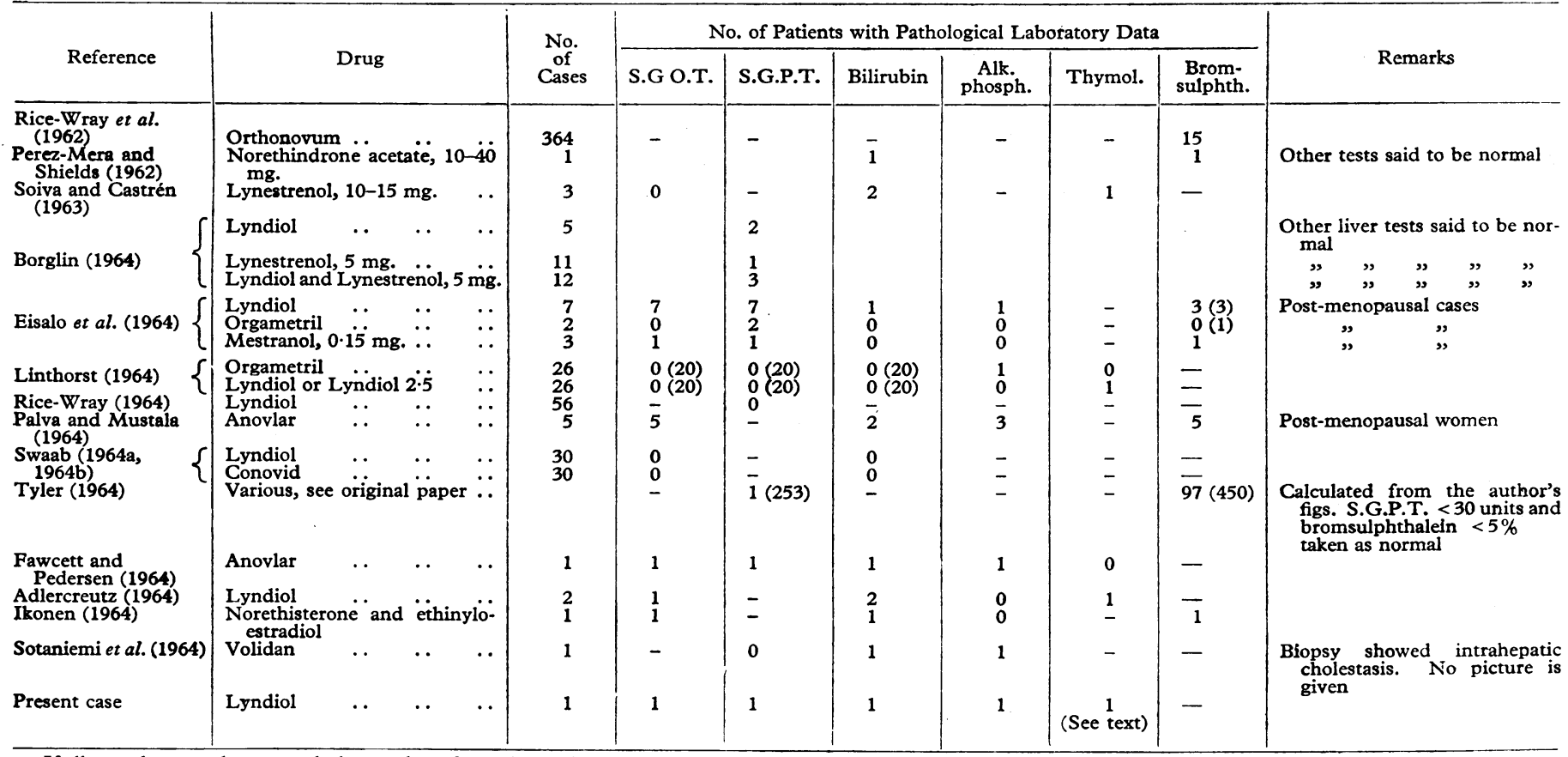

If all cases have not been tested, the number of tested cases is given within parentheses; - means not reported.

Pharmacological data : Orthonovum contains $0.06 \mathrm{mg}$. 3-methoxy ethinyloestradiol and $10 \mathrm{mg}$. norethindrone. Lyndiol contains $0.15 \mathrm{mg}$. mestranol and $5 \mathrm{mg}$. lynoestrenol. Lyndiol mite contains half the dose of Lyndiol (Lyndiol 2.5). Orgametril contains $5 \mathrm{mg}$. lynoestrenol. Anovlar contains $0.05 \mathrm{mg}$. ethinyloestradiol and 4 mg. norethisterone prescribed.

in Lyndiol-induced liver disease. Biopsy data during the icteric phase of Lyndiol jaundice seem to be restricted to the present case and that of Sotaniemi et al. (1964). Their biopsy is said to have shown intrahepatic cholestasis, but no picture is given. The experience with the thymol test is also limited.

It should be remembered in evaluating these data that in the present case and in the solitary cases at the end of the Table the relation between jaundice and drug is not unquestionable.

\section{Summary}

A case of jaundice which appeared during treatment with the oral contraceptive Lyndiol is reported. It is probable that the jaundice was caused by the drug. Laboratory data of the case include elevated levels of bilirubin, alkaline phosphatases, and transaminases. Biopsy of the liver showed intrahepatic cholestasis and hepatocellular damage. The case is compared with similar cases in the literature.

\section{REFERENCES}

Adlercreutz, H. (1964). Nord. Med., 72, 1004.

Borglin, N. (1964). Int. F. Fert., 9, 17.

Drill, v. A. (1963). Ann. N.Y.' Acad. Sci., 104, 858.

Eisalo, A., Järvinen, P. A., and Lunkkainen, T. (1964). Brit. med. 7., 2, 426.

Fawcett, J. W., and Perersen, D. L. (1964). Ibid., 2, 755.

Hall, M. J. (1960). Amer. J. clin. Path., 34, 313.

Ikonen, E. (1964). Acta obstet. gynec. scand., 43, Suppl. Na. 5.

Lancet, 1962, 1, 1056 .

Linthorst, G. (1964). Brit. med. 7., 2, 920.

Palva, I. P., and Mustala, O. O. (1964). Ibid., 2, 688.

Perez-Mera, R. A., and Shields, C. E. (1962). New Engl. ₹. Med., 267, 1137.

Rice-Wray, E. (1964). Brit. med. 7., 2, 1011

Rice-Wray, E. (1964). Brit. med. F., 2, 1011. 7. Amer. med. Ass., 180, 355 .

Smetana, H. F. (1963). Ann. N.Y. Acad. Sci., 104, 821.

Soiva, K., and Castrén, O. (1963). Ann. Chir. Gynaec. Fenn., 52, 376. Sotaniemi, E., Kreus, K. E., and Scheinin, T. M. (1964). Brit. med. F., 2, 1264 .

Swaab, L. (1964a). Int. F. Fert., 9, 107.

Tylo4b). Brit. med. 7., 2, 755 .

Zimmerman, H. J. (1963). Ann. N.Y. Acad. Sci., 104, 954.

\title{
Erythropoietin in Concentrates of Urine From Healthy Persons
}

\author{
PER HAAVARDSHOLM FINNE,* M.D.
}

\section{Brit. med. F., 1965, 1, 697-699}

The existence of a humoral factor (erythropoietin) controlling erythropoiesis is well established. There have, however, been some difficulties in demonstrating erythropoietin in blood from moderately anaemic or non-anaemic persons. A dual mechanism of erythropoietic regulation has therefore been suggested (Stohlman, 1959; Borsook et al., 1962), one mechanism based on erythropoietin acting in severe anaemias, another under normal conditions. Not all investigators agree with this theory (Gurney et al., 1961). The difficulties in demonstrating a correlation between the plasma erythropoietin levels and the haemoglobin concentrations in moderately anaemic persons have also been thought by some investigators to be due to the crudeness of the erythropoietin assay methods used to-day (Van Dyke et al., 1961).

If erythropoietin is the only humoral factor regulating the rate of erythrocyte formation under physiological conditions it should be demonstrable also in normal persons. Because of * Children's Department, Paediatric Research Institute, Rikshospitalet,
Oslo, Norway. 